\title{
NGHIÊN CỨU ĐẶC TÍNH MÔ BỆNH HỌC ĐỘNG MẠCH VỊ MẠC NỐI PHẢI SỬ DỤNG LÀM CẦU NỐI TRONG PHẪU THUẬT BẤC CẦU MẠCH VÀNH TẠI BỆNH VIỆN CHỌ RÃ̃Y
}

Đoàn Văn Phụng*, Trần Quyết Tiến**

\section{TÓM TẮT}

Chúng tôi thu thập các đoạn ở phần xa của ĐMVMNP trên 74 bệnh nhân được phẫu thuật bắc cầu mạch vành có sử dụng loại mảnh ghép ĐMVMNP làm cầu nối mạch vành. Tất cả các mẫu được gửi làm giải phẫu bệnh để phân tích các đặc tính cơ bản mô học và mô bệnh học dưới kính hiển vi điện tử có ghi hình. Các đặc điểm về hình thái học như chiều dài, kích thước lòng trong, độ dày các lớp của ĐMVMNP được đo đạt bằng kính hiển vi điển tử tại Khoa Giải phẫu bệnh, bệnh viện Chợ Rẫy. Mô bệnh học bao gồm tăng sinh nội mạc, xơ vữa động mạch và vôi hóa động mạch được đánh giá theo tiêu chuẩn của Hiệp Hội Xơ Vữa Động Mạch cải biến của Hoa Kỳ (AHA/ACC 2011). Các yếu tô nguy cơ ảnh hưởng đến bệnh lý mô học của ĐMVMNP được phân tích bằng thống kê y học. Độ dài trung bình các ĐMVMNP là 23,9 $\pm 3,3 \mathrm{~cm}$. Đường kính trung bình lòng trong của ĐMVMNP ở phần xa là $1,85 \pm 0,69 \mu \mathrm{m}$; độ dày trung bình lớp nội mạc là $70,1 \pm 40 \mu \mathrm{m}$; độ dày trung bình lớp trung mạc là $210,5 \pm 110,3 \mu \mathrm{m}$; độ dày toàn bộ thành động mạch trung bình là 298,6 $\pm 121,3 \mu \mathrm{m}$. Số sợi đàn hồi trong lớp trung mạc trung bình là $4,3 \pm 1,1$; số khoảng hở của lớp màng đáy trung bình là $54 \pm$ 10,8. Đặc điểm mô bệnh học ĐMVMNP bao gồm tăng sinh nội mạc 56 mẫu (75,7\%), nhưng đa số tăng sinh nội mạc nhẹ 94,6\%. Các tổn thương nặng là xơ vữa động mạch và vôi hóa động mạch chiếm tần suất thấp lần lượt là 3 mẫu $(4,1 \%)$ và 2 mẫu $(2,7 \%)$. Kết quả phân tích mối liên quan giữa các yếu tố nguy cơ và bệnh lý đi kèm của các bệnh nhân được lấy ĐMVMNP làm cầu nối đối với kết quả mô bệnh học của ĐMVMNP ghi nhận chỉ có yếu tố bệnh phổi tắc nghẽn mãn tính (COPD) có ảnh hưởng làm tăng nguy cơ bệnh lý xơ vữa động mạch ở ĐMVMNP có ý nghĩa với $\mathrm{OR}=35$; khoảng tin cậy 95\% $(1,13$ - 117) $(\mathrm{p}<0,025)$.

Tù̀ khóa: Phẫu thuật bắc cầu mạch vành, Động mạch vị mạc nối phải, Mô học

\section{SUMMARY}

\section{STUDY OF HISTO-PATHOLOGY OF THE \\ RIGHT GASTROEPIPLOIC ARTERY FOR \\ USING CORONARY ARTERY BYPASS \\ GRAFTING IN CHO RAY HOSPITAL}

The mean of RGEA's length was 23,9 $\pm 3,3$ $\mathrm{cm}$. The mean of lumen diameter at the most distal anastomosis was $1,85 \pm 0,69 \mu \mathrm{m}$; mean width of intima $70,1 \pm 40 \mu \mathrm{m}$; mean width of media $210,5 \pm 110,3 \mu \mathrm{m}$; mean wall thickness, $298,6 \pm 121,3 \mu \mathrm{m}$. The mean number of elastic lamellae in the media was $4,3 \pm 1,1$. The mean number of discontinuities in the circumferential internal elastic lamina was $54 \pm 10,8$. The histopathological properties of RGEA included: intimal hyperplasia in 56 segments $(75,7 \%)$, but most of segments were mild intimal hyperplasia 94,6\%. The severe pathological properties of RGEA with atherosclerosis, arterial calcification were found very rare 3 segments $(4,1 \%)$ and 2 segments $(2,7 \%)$ respectively. The results of risk factors associated with histo-pathological properites analysis were recorded that the chronic obstructive pulmonary disease (COPD) was independently

\footnotetext{
* Khoa HSPTT Trẻ em BV Chơ R Rãy

** BV Chơ R R̂̃y

Ngườ chịu trách nhiệm khoa học: PGS.TS. Trần Quyết Tiến

Ngày nhận bài: 01/05/2018 - Ngày Cho Phép Đăng: 20/05/2018

Phản Biện Khoa học: GS.TS. Bùi Đức Phú

PGS.TS. Đặng Ngọc Hùng
} 
associated with atherosclerosis damage $\mathrm{OR}=35$; confident rate $95 \%(1,13-117)(\mathrm{p}<0,025)$.

Key Words: Coronary bypass surgery, Right gastroepiploic artery, Histology

\section{GIỚI THIỆU}

Phẫu thuật bắc cầu mạch vành điều trị bệnh lý hẹp mạch vành ngày càng trở nên phổ biến tại nhiều nước trên thế giới cũng như tại Việt Nam. Việc lựa chọn vật liệu làm cầu nối là một trong các yếu tố quyết định sự thành công của PTBCMV [13]. Nghiên cứu các đặc tính cơ bản của vật liệu làm cầu nối bao gồm chiều dài, cấu trúc thành động mạch, bệnh lý mô học của động mạch trước khi ứng dụng làm cầu nối trong phẫu thuật bắc cầu động mạch vành là rất cần thiết nhằm mang lại hiệu quả tối ưu cho kết quả phẫu thuật [2],[8]. Động mạch vị mạc nối phải đã và đang sử dụng làm cầu nối mạch vành tại nhiều nước trên thế giới.Tuy nhiên, việc nghiên cứu loại cầu nối này tại Việt Nam chỉ mới bắt đầu tại $\mathrm{BV}$ Chợ Rẫy và chưa có nghiên cứu nào đánh giá về các đặc tính cơ bản của chúng. Từ những lý do trên, chúng tôi thực hiện "Nghiên cứu đặc tính mô bệnh học của động mạch vị mạc nối phải sủ dụng làm cầu nối trong PTBCMV".

\section{PHƯƠNG PHÁP}

Thiết kế nghiên cứu: Quan sát- mô tả- cắt ngang

Mẫu nghiên cứu: 74 mẫu động mạch vị mạc nối phải ở phần đầu xa.

Tiến hành:

+ Xử lý các đoạn động mạch VMNP và làm tiêu bản mô hoc:

Động mạch VMNP đã được phẫu tích, trước khi cắt làm miệng nối sẽ được đo chiều dài xem xét đủ để thực hiện miệng nối vành, sẽ được kẹp 2 clip, một ở đầu tận và một ở vị trí sẽ cắt làm miệng nối. Tiếp theo, mẫu này được cố định trong dung dịch formalin $10 \%$ trung tính từ 5 đến 7 ngày. Rửa lại một lần bằng nước muối sinh lý $0,9 \%$. Khử nước trong các mẫu động mạch bằng cồn hay xylene. Cố định mẫu để cắt bằng paraffin.

Cắt vi phẫu với độ dày thích hợp khoảng 1 $\mu \mathrm{m}$. Các mặt cắt được đặt lên 2 tiêu bản. Một tiêu bản sẽ được nhuộm Hematoxyllin -eosin (H-E), đánh giá tổn thương bệnh lý và tiêu bản còn lại nhuộm Trichrome để xác định cấu trúc mô học của động mạch, các sợi đàn hồi trong lớp trung mạc.

Các tiêu bản sẽ được quan sát dưới kính hiển vi quang học ở độ phóng đại $10 \mathrm{X}$ lần, $20 \mathrm{X}$ lần và $40 \mathrm{X}$ lần. Kính hiển vi quang học có camera chụp lại hình ảnh mô học kết nối với máy tính và cài đặt phần mềm để đo đạc các kích thước của động mạch.

+ Phân tích kết quả mô học và bệnh lý mô học động mạch VMNP gồm các giá trị: Xác định hình thái học của động mạch VMNP bao gồm các giá trị: đường kính lòng động mạch, độ dày của lớp nội mạc, lớp trung mạc, độ dày thành mạch.

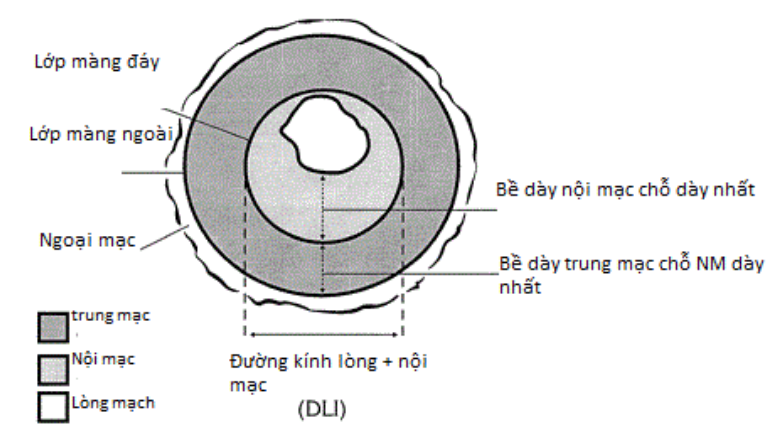

Hình 2.1: Phwơng thức xác định các kích thwớc của động mạch vị mạc nối phải

Xác định cấu trúc mô học của động mạch VMNP bao gồm lớp ngoại mạc, trung mạc và nội mạc, ghi nhận số lượng các khoảng không liên tục ở lớp màng đáy của nội mạc.

Xác định số lượng sợi đàn hồi trong lớp trung mạc

+ Phân tích mô bệnh học của động mạch bao gồm 3 thương tổn: Tăng sinh nội mạc, xơ vữa động mạch và vôi hóa động mạch.

*Tăng sinh nội mạc: được xác định khi độ 
dày của lớp nội mạc lớn hơn $20 \mu \mathrm{m}$ và chiếm hơn $1 / 4$ chu vi của mặt cắt

*Đánh giá múc độ tăng sinh nội mạc bằng tỉ lệ độ giữa độ dày của lớp nội mạc và độ dày của lớp trung mạc tại vị trí nội mạc dày nhất gồm 5 mức độ:

- Độ 0: giá trị <0,25 ( không hay tăng sinh nội mạc rất nhẹ)

- Độ 1: giá trị từ 0,25- 0,5 (nhẹ)

\section{KẾT QUẢ NGHIÊN CÚU}

\section{1. Đặc điểm dịch tể bệnh nhân được gửi mẫu phân tích:}

\begin{tabular}{lcc}
\hline Đặc điểm & Tần số (n=74) & Tỷ lệ \% \\
\hline Giới (Nam) & 56 & 75,7 \\
Tuổi (năm) & $58,4 \pm 7,8$ & \\
Tăng huyết áp & 62 & 83,3 \\
Đái tháo đường type 2 & 32 & 43,2 \\
Rối loạn mỡ máu & 26 & 35,1 \\
Bệnh phổi tắc nghẽn mãn tính & 2 & 2,7 \\
Suy thận mãn & 1 & 1,4 \\
Bệnh động mạch ngoại vi & 1 & 1,4 \\
Tai biến mạch máu não cũ & 6 & 8,1 \\
Hút thuốc lá & 13 & 17,6 \\
\hline
\end{tabular}

Nhận xét: Tăng huyết áp trên các bệnh nhân gửi mẫu chiếm tỷ lệ cao với $83,3 \%$, kế tiếp là bệnh lý tiểu đường ở 32 trường hợp lấy mẫu chiếm tỷ lệ 43,2\%.

Rối loạn mỡ máu ghi nhận ở 26 trường hợp được lấy mẫu chiếm tỷ lệ 35,1\%. Hút thuốc lá 13 trường hợp chiếm tỷ lệ $(17,6 \%)$.

\section{2. Đặc điểm mô học các mẫu động mạch nghiên cứu:}

\begin{tabular}{lc}
\hline Đặc điểm & Trung bình \pm độ lệch chuẩn \\
\hline Chiều dài ĐMVMNP $(\mathrm{mm})(\mathrm{n}=117)$ & $23,9 \pm 3,3 \mathrm{~mm}$ \\
Đường kính lòng trong $(\mathrm{mm})$ & $1,85 \pm 0,69 \mathrm{~mm}$ \\
Độ dày nội mạc (intima)(micromet) & $70,1 \pm 40,0 \mu \mathrm{m}$ \\
Độ dày trung mạc (media)(micromet) & $210,5 \pm 110,3 \mu \mathrm{m}$ \\
Số sợi đàn hồi trong lớp trung mạc & $4,3 \pm 1,1$ \\
Số khoảng hở màng đáy & $54 \pm 10,8$ \\
\hline
\end{tabular}

Nhận xét : Chiều dài của các động mạch vị mạc nối phải ghi nhận trên tất cả 117 bệnh nhân làm cầu nối mạch vành tương đối dài với giá trị trung bình là 23,9 $\pm 3,3 \mathrm{~mm}$. 
Kích thước lòng trong đoạn xa, chỗ làm miệng nối mạch vành đích trung bình là 1,85 $\pm 0,69$ mm.

Độ dày nội mạc trung bình là $70,1 \pm 40,0 \mu \mathrm{m}$ và của trung mạc là $210,5 \pm 110,3 \mu \mathrm{m}$.

Số khoảng hở ở lớp màng đáy nhiều với giá trị trung bình là $54 \pm 10,8$ khoảng.

Đa số các mẫu ĐMVMNP thu được thuộc loại động mạch cơ vì số lượng sợi đàn hồi trong lớp trung mạc ít giá trị trung bình là 4,3 $\pm 1,1$ sợi.

\section{3. Đặc điểm mô bệnh học của các mẫu ĐMVMNP:}

\begin{tabular}{lcc}
\hline Đặc điểm bệnh học & Tần số (n=74) & Tỷ lệ \% \\
\hline Tăng sinh nội mạc & 56 & 75,7 \\
Mức độ tăng sinh nội mạc & & 32,4 \\
Độ 0 & 24 & 47,3 \\
Độ 1 & 35 & 14,9 \\
Độ 2 & 11 & 4,1 \\
Độ 3 & 3 & 1,4 \\
Độ 4 & 1 & \\
Trung bình tỷ số độ dày nội mạc/ độ dày & & $0,36 \pm 0,23$ \\
trung mạc (chỗ nội mạc dày nhất) & & 4,1 \\
Tổn thương xơ vữa động mạch & 3 & 2,7 \\
Tổn thương vôi hóa trung mạc & 2 & \\
\hline
\end{tabular}

Nhận xét: Tăng sinh nội mạc (bề dày nội mạc lớn hơn $20 \mu \mathrm{m}$ chiếm hơn $1 / 4 \mathrm{chu}$ vi lòng mạch) được ghi nhận trên 56 mẫu chiếm tỷ lệ $75,7 \%$.

Tỷ lệ độ dày nội mạc / độ dày trung mạc (ở vị trí nội mạc dày nhất) để phân loại mức độ tăng sinh nội mạc, giá trị trung bình là $0,36 \pm 0,23$.

Chúng tôi phân loại mức độ tăng sinh nội mạc dựa trên tỷ lệ này trong đó độ 1 chiếm ưu thế với tỷ lệ $47,3 \%$.

Tổn thương xơ vữa ghi nhận ở 3 mẫu chiếm tỷ lệ $4,1 \%$ và tổn thương vôi hóa động mạch là 2 mẫu chiếm tỷ lệ $1,4 \%$.

4. Mối liên quan giữa yếu tố nguy cơ, bệnh lý đi kèm đối với tổn thương xơ vữa động mạch

\begin{tabular}{lccc}
\hline Đặc điểm & OR & KTC & Giá trị p \\
\hline Giới (nữ) & 6,87 & $0,62-153,7$ & 0,125 \\
Tuổi (>70 tuổi) & 1,10 & $0,94-1,32$ & 0,266 \\
Tăng huyết áp & - & - & - \\
Đái tháo đường type 2 & - & - & - \\
Rối loạn mỡ máu & - & - & - \\
Bệnh phổi tắc nghẽn mãn tính & $\mathbf{3 5 , 0}$ & $\mathbf{1 , 1 3 - 1 1 7 0}$ & $\mathbf{0 , 0 2 5}$ \\
\hline
\end{tabular}

Nhận xét : Qua phân tích các yếu tố nguy cơ, bệnh lý đi kèm trước mổ chúng tôi ghi nhận có mối liên quan giữa bệnh lý phổi tắc nghẽn mãn tính có liên quan đến xơ vữa động mạch với độ mạnh $\mathrm{OR}=35 ; \mathrm{p}=0,025$.

Các yếu tố còn lại khác không ghi nhận có mối liên quan với tổn thương xơ vữa động mạch. 


\section{IV.BÀN LUẬN}

Khảo sát các đặc tính cơ bản của cầu nối bao gồm các đặc điểm mô học, mô bệnh học, hình thái học được xem là một trong những yếu tố quan trọng quyết định kết quả lâu dài của phẫu thuật bắc cầu mạch vành. Sự phù hợp về kích thước, cấu trúc thành mạch giữa động mạch làm cầu nối và động mạch vành, tạo điều kiện cho các phẫu thuật viên tim mạch thực hiện các miệng nối thuận lợi cũng như giúp điều chỉnh dòng chảy tốt của cầu nối mạch vành [2],[3],[4],[7].

\section{Về độ dài $Đ M V M N P$}

Chúng tôi đo đạc toàn bộ chiều dài của động mạch vị mạc nối phải được lấy trước khi làm cầu nối trên 117 bệnh nhân phẫu thuật bắc cầu mạch vành. Kết quả ghi nhận chiều dài của cầu nối này khá tốt trung bình là $23,9 \pm 3,3 \mathrm{~cm}$. Như vậy, với chiều dài của ĐMVMNP như trên là phù hợp để làm cầu nối mạch vành. Một số nghiên cứu trên thế giới như Mills và cộng sự ghi nhận chiều dài trung bình của động mạch này khi sử dụng tại chỗ là $23,7 \mathrm{~cm}$, còn dạng cắt rời là $17,7 \mathrm{~cm}$. Theo Brenda, chiều dài của động mạch này khi sử dụng làm cầu nối dao động từ 19,32 $\mathrm{cm}$ đến $20 \mathrm{~cm}$ [4],[10]. Suma và cộng sự trong một báo cáo của mình ghi nhận $95 \%$ số trường hợp có chiều dài động mạch vị mạc nối phải lớn hơn $1 / 2$ chiều dài bờ cong lớn của dạ dày, $34 \%$ các trường hợp có độ dày lớn hơn $2 / 3$ chiều dài bờ cong lớn [11],[12],[13].

\section{Về cấu trúc hình thái ĐMVMNP}

Đường kính lòng trong trung bình của ĐMVMNP trong nghiên cứu của chúng tôi là $1,85 \pm 0,69 \mathrm{~mm}$. Theo nghiên cứu của Mills và cộng sự, đường kính lòng trong của ĐMVMNP thay đổi từ 1,5 đến $3,25 \mathrm{~mm}$ và giá trị trung bình là $2,14 \mathrm{~mm}$ [10]. Nghiên cứu của Van Son và cộng sự tìm thấy kích thước lòng trong của ĐMVMNP ở đoạn xa là $1,8 \mathrm{~mm}$; đoạn giữa là 2,2 $\mathrm{mm}$ và đoạn gần là $2,7 \mathrm{~mm}$ [14]. Tác giả Santoff trong nghiên cứu của mình ghi nhận đường kính lòng của động mạch này thay đổi từ 1,8 đến 2,5 mm. Một nghiên cứu tại Nhật của Kinoshita ghi nhận đường kính lòng ĐMVMNP tốt với giá trị trung bình là $3,8 \mathrm{~mm}$ [13]. Như vậy chính sự phù hợp này tạo điều kiện cho việc thực hiện miệng nối mạch vành một cách dễ dàng hơn, góp phần nâng cao chất lượng miệng nối, tránh sự hẹp sớm cầu nối là một trong những nguyên nhân thất bại của cầu nối [4].

\section{Về đặc tính lớp trung mạc, nội mạc DMVMNP}

Lớp trung mac của động mạch chứa các tế bào cơ trơn và các sợi đàn hồi. Theo đó, dựa vào số lượng các sợi đàn hồi trong lớp này, chúng tôi có thể tìm được phân loại động mạch là loại cơ, loại đàn hồi hay loại hỗn hợp [8],[9]. Trong nghiên cứu này trên 74 mẫu thu được, số lượng sợi đàn hồi ở lớp trung mạc trung bình là $4,3 \pm$ 1,1 sợi, thay đổi từ 2 sợi đến 6 sợi. Như vậy, đa số các mẫu ĐMVMNP là loại động mạch cơ. Nghiên cứu của Kinoshita và cộng sự tại Nhật thì số lượng sợi đàn hồi trong lớp trung mạc là $4,2 \pm$ 18 [13]. Một tỷ lệ lớn mẫu động mạch tìm thấy cũng là loại động mạch cơ. Kết quả của chúng tôi đã tìm thấy được yếu tố này cũng đã có thể góp phần khuyến cáo các phẫu thuật viên tim mạch trong việc chuẩn bị kỹ cầu nối bằng động mạch vị mạc nối phải trước khi thực hiện miệng nối vành, tránh co thắt cầu nối sau mổ có thể làm thất bại cuộc mổ.

Lớp nội mạc bao gồm các tế bào nội mạc, mô liên kết dưới nội mạc và lớp màng đáy hay là màng đàn hồi trong, mỗi thành phần trong lớp nội mạc có vai trò và chức năng góp phần xác định bệnh lý của động mạch làm cầu nối [14]. Lớp màng đáy của nội mạc mạch máu là một màng đàn hồi có các khoảng hở thay đổi tùy theo loại động mạch. Khảo sát các khoảng hở trong lớp màng đáy nội mạc cũng có ý nghĩa quan trọng trong cơ chế bệnh sinh của bệnh lý mạch máu làm cầu nối. Theo một số nghiên cứu cơ bản chứng minh lớp màng đáy ở động mạch ngực trong trái được xem là bền vững do có ít khoảng hở, giúp ngắn cản các tế bào cơ trơn trong lớp trung mạc di chuyển vào lớp nội mạc, ngăn chặn quá trình tăng sinh nội mạc và xơ vữa động mạch. Ngoài ra, do đặc tính loại động mạch ngực trong trái là loại động mạch đàn hồi, chứa rất ít tế bào cơ nên cũng hạn chế được sự di chuyển các tế bào xuyên qua lớp màng đáy vào nội mạc. Hai yếu tố trên lý 
giải được lý do tại sao động mạch ngực trong trái tránh được bệnh lý mạch máu như tăng sinh nội mạc và xơ vữa động mạch. Từ cơ chế này, chúng tôi cũng đã khảo sát các khoảng hở trên mẫu nghiên cứu động mạch vị mạc nối phải [8],[12].

Nghiên cứu của chúng tôi ghi nhận số lượng các khoảng hở màng đáy trung bình là $54 \pm$ 10,8 khoảng. Theo nghiên cứu của Van Son và cộng sự, số lượng khoảng hở lớp màng đáy ở đầu xa của ĐMVMNP là $58 \pm 17$ khoảng, đoạn giữa là $93 \pm 29$ khoảng và đoạn gần là $86 \pm 30$ khoảng. Đối với động mạch ngực trong trái, nhóm nghiên cứu ghi nhận các khoảng hở ở đoạn động mạch đàn hồi là 21 khoảng, động mạch hỗn hợp 40 khoảng và động mạch cơ là 89 khoảng [14].

\section{Đặc điểm bệnh lý $Đ M V M N P$}

Xác định độ dày của lớp nội mạc giúp đánh giá sự hiện diện tăng sinh nội mạc [16]. Trong nghiên cứu này, chúng tôi đo được độ dày nội mạc trung bình trên tất cả các mẫu là $70,7 \mu \mathrm{m}$, và độ dày trung bình của lớp trung mạc là $210,5 \mu \mathrm{m}$. Theo nghiên cứu của tác giả Malhotra và cộng sự, độ dày trung bình của lớp nội mạc là $90 \mu \mathrm{m}$. Nakajima trong nghiên cứu của mình xác định giá trị này là $71,7 \mu \mathrm{m}$, trung mạc là $164,8 \mu \mathrm{m}$. Nghiên cứu của Van Son và cộng sự ghi nhận tăng sinh nội mạc ở ĐMVMNP ở mức trung bình với giá trị là $95 \mu \mathrm{m}$ và độ dày nội mạc là $395 \mu \mathrm{m}$ [14]. Một nghiên cứu tại Nhật của Kinoshita và cộng sự thì độ dày nội mạc ghi nhận là $82 \mu \mathrm{m}$ và trung mạc là $167 \mu \mathrm{m}[6],[7],[11],[14]$.

Chúng tôi ghi nhận tỷ lệ tăng sinh nội mạc ở các mẫu nghiên cứu là $75,7 \%$ các trường hợp, tỷ lệ độ dày nội mạc và trung mạc trung bình ở mức thấp là 0,36 . Từ kết quả này, chúng tôi tìm ra mức tăng sinh nội mạc với phần lớn tăng sinh nội mạc ở mức độ thấp $($ độ 0,1$)$ không tăng sinh nội mạc hay tăng sinh rất nhẹ là 79,7\%; độ 2 tăng sinh nội mạc là $14,9 \%$. Tăng sinh nội mạc nặng, cấp độ 3,4 chỉ chiếm $5,5 \%$. Nghiên cứu của Nakajima và đồng nghiệp, động mạch VNMP có nội mạc dầy hơn động mạch ngực trong trái [10]. Còn theo Van Son và cộng sự, tăng sinh nội mạc ở ĐMVMNP tìm thấy ở mức độ nhẹ đến trung bình, tăng sinh nội mạc gặp nhiều ở động mạch cơ hơn động mạch đàn hồi hay động mạch dạng hỗn hợp với tần suất tương ứng là $25,6 \% ; 16,7 \%$ và $15,3 \%$ [14].

Tổn thương $x o$ vũ̃a động mạch và vôi hóa động mach trên các mẫu động mạch nghiên cứu. Nghiên cứu trên 74 mẫu động mạch vị mạc nối phải ở đoạn xa của các động mạch vị mạc nối phải thu được ghi nhận tần suất xơ vữa động mạch là 3 mẫu chiếm tỷ lệ $4,1 \%$, vôi hóa động mạch là 2 mẫu chiếm tỷ lệ $2,7 \%$. Theo Kinoshita và cộng sự khảo sát trên 33 mẫu ĐMVMNP ghi nhận tỷ lệ xơ vữa động mạch là $18,1 \%$ và vôi hóa động mạch là $9 \%$ [11]. Theo Nakajima và cộng sự tìm thấy có tổn thương xơ vữa động mạch và vôi hóa động mạch ở ĐMVMNP, trong khi động mạch ngực trong không ghi nhận tổn thương này [10]. Còn theo Mills và Lytle, không ghi nhận tổn thương xơ vữa và vôi hóa trên các đoạn ĐMVMNP, mô học giống với động mạch ngực trong có thể sử dụng làm cầu nối mạch vành với độ bền lâu dài tốt [9],[10].

Song song với việc khảo sát các đặc tính cơ bản trên, trong nghiên cứu này chúng tôi còn phân tích mối liên quan giữa các yếu tố nguy co và bệnh lý đi kèm với bệnh lý của động mạch $V M N P$ trong nhóm nghiên cứu. Theo đó, chúng tôi chỉ ghi nhận có một mối liên quan giữa bệnh lý bệnh phổi tắc nghẽn mãn tính lên tổn thương xơ vữa động mạch VMNP với $\mathrm{OR}=35$ ( $\mathrm{p}<$ $0,025)$. Theo Nakajima, bệnh lý đái tháo đường loại 2 có liên quan với tình trạng tăng sinh nội mạc ở động mạch VMNP. Xét mối liên quan này với các cầu nối bằng động mạch khác của các nghiên cứu trên thế giới, chúng tôi cũng ghi nhận như sau: đối với động mạch quay, theo Ruengsakulrach, bệnh lý động mạch ngoại vi và hút thuốc lá có ảnh hưởng đến tăng sinh nội mạc,còn theo Kay, tuổi bệnh nhân hơn 70 có liên quan đến vôi hóa trung mạc. Đối với động mạch ngực trong, yếu tố tuổi già hơn 70 và đái tháo đường loại 2 có liên quan tăng sinh nội mạc, bệnh lý mạch máu ngoại vi và rối loạn mỡ máu có ảnh hưởng đến tổn thương xơ vữa động mạch. Như vậy trong hầu hết các nghiên cứu, bệnh lý động mạch VMNP ít chịu ảnh hưởng của các yếu tố nguy cơ hay bệnh lý đi kèm ở các bệnh nhân được khảo sát. 


\section{KẾT LUẬN}

Chúng tôi thấy rằng xét về gốc độ mô học và bệnh lý mô học, ĐMVMNP mang những đặc tính cơ bản phù hợp cho một cầu nối bắc cầu mạch vành từ chiều dài, kích thước lòng trong, độ dày các lớp của thành mạch phù hợp tương ứng với động mạch vành đích. Tồn thương bệnh lý động mạch vị mạc nối phải như tăng sinh nội mạc nặng, xơ vữa hoặc vôi hóa trung mạc chiếm tần suất ít do đó được nhiều nghiên cứu trên thế giới xem là cầu nối có độ bền cao. Ngoài ra, qua phân tích các yếu tố nguy cơ, bệnh lý đi kèm trước mổ chúng tôi ghi nhận có mối liên quan giữa bệnh lý phổi tắc nghẽn mãn tính có liên quan đến xơ vữa động mạch. Do đó, cần lưu ý cân nhắc sử dụng cầu nối bằng ĐMVMNP cho các bệnh nhân bị hẹp mạch vành có đi kèm bệnh phổi tắc nghẽn mãn tính.

\section{TÀI LIỆU THAM KHẢO}

1. Lê Văn Cường, Võ Thành Nghĩa, Nguyễn Gia Ninh (2011): "Nghiên cứu hình dạng, vị trí, kích thước các động mạch dùng bắc cầu trong bệnh tắc hẹp động mạch vành tim" $Y$ hoc TP Hồ Chí Minh, phụ bản của tập 15 (số 1) tr 262-267.

2. Appleson T, Hill RV (2012): “ Histological comparision of the candidate arteries for bypass grafting of the posterior interventricular artery". Anat Sci Int vol 87: pp 150-4

3. Benedetto U, Raja SG, Albanese A, Amrani M, Biondi-Zoccai G, Frati G (2015): "Searching for the second best graft for coronary artery bypass surgery: a network meta-analysis of randomized controlled trials". Eur $J$ Cardiothorac Surg. Vol 47: pp 59-65:

4. Brenda Martinez G, Cynthia GR, Alejandro QG, Victor ER, Claudia NE, Rodrigo EE, Santo GP (2017): "Conduits used in coronary artery bypass grafting: a review of morphological studies". Ann Thorac Cardiovasc Surg. Vol 178: pp 129-35

5. Cater CM, Gitter R, Gett K (1996): "Spasm of the gastroepiploic artery use for coronary artery bypass grafting", Am J Cardiol, Vol 77, page $1022-23$

6. Dignan RJ, Yeh T, Jr, Dyke CM, et al (1992): "Reactivity of gastroepiploic and internal mammary arteries: relevance to coronary artery bypass grafting”. J Thorac Cardiovasc Surg. Vol 103: pp 116-22

7. Gaudino M, Taggart D, Suma H, Puskas JD, Crea F, Massetti M (2015): "The choice of conduits in coronary artery bypass surgery". $J$ Am Coll Cardiol. ; Vol 66: pp 1729-37

8. 66. Gou-Wei H (2006): "Consideration in the choice of arterial grafts". In: Gou-Wei H, editor. Arterial grafting for coronary artery bypass surgery. $2^{\text {nd }}$ ed. Berline, Heidelberg: Springer, pp 81-6

9. He GW (1999): “Arterial grafts for coronary artery bypass grafting: biological characteristics, functional classification, and clinical choice". Ann Thorac Surg; Vol 67: pp 277-84

10. Mc Cormack D, Ham A (1987): “Ham's Histology. $9^{\text {th }}$ ed. Philadelphia": Lippincott Williams and Wilkins, pp 444

11. Suma H, Fukumoto H, Takeuchi A (1987): "Coronary artery bypass grafting by utilizing in situ right gastroepiploic artery: basic study and clinical application". Ann Thorac Surg; Vol 44: pp 394-7

12. Suma H, Takanashi R (1990): "Arteriosclerosis of the gastroepiploic and internal thoracic arteries". Ann Thorac Surg ; Vol 50: pp 413-6 (113)

13. Suma H, Wanibuchi Y, Furuta S, Isshiki T, Yamaguchi T, Takanashi R (1991): "Comparative study between the gastroepiploic and the internal thoracic artery as a coronary bypass graft. Size, flow, patency, histology". Eur $J$ Cardiothorac Surg. Vol 5: pp 244-7

14. Van Son JA, Smedts F, Vincent JG, van Lier HJ, Kubat K (1990): "Comparative anatomic studies of various arterial conduits for myocardial reascularization". $J$ Thorac Cardiovasc Surg. Vol 99: pp 703-7

15. Viral M. Bhanvivadia, Nandini J, Desai, Neeru M. Agarwal (2013): "Study of coronary atherosclerosis by Modified American Heart Association classification of atherosclerosis- An autopsy study", J Clinical and Diagnostic Research, Vol 7(11), page 2494-97

16. Zipes L, Braunwald B (2002): Braunwald's Heart Disease. A textbook of Cardiovascular medicine. Vol $17^{\text {th }}$ ed. 